Case Report

\title{
Peripheral T-Cell Lymphoma of the Submandibular Salivary Gland as an Unusual Manifestation of Richter's Syndrome: A Case Report and Literature Review
}

\author{
Vadim R. Gorodetskiy, ${ }^{1}$ Natalya A. Probatova, ${ }^{2}$ and Tatiana T. Kondratieva ${ }^{2}$ \\ ${ }^{1}$ Department of Intensive Methods of Therapy, V.A. Nasonova Research Institute of Rheumatology, Russian Academy of \\ Medical Sciences, Kashirskoye shosse 34A, Moscow 115522, Russia \\ ${ }^{2}$ Department of Pathology, N.N. Blokhin Russian Cancer Research Center, Russian Academy of Medical Sciences, Kashirskoye \\ shosse 24, Moscow 115478, Russia
}

Correspondence should be addressed to Vadim R. Gorodetskiy; gorodetskiyblood@mail.ru

Received 31 July 2017; Accepted 22 October 2017; Published 3 December 2017

Academic Editor: Kazunori Nakase

Copyright ( 2017 Vadim R. Gorodetskiy et al. This is an open access article distributed under the Creative Commons Attribution License, which permits unrestricted use, distribution, and reproduction in any medium, provided the original work is properly cited.

\begin{abstract}
Richter's syndrome is the development of high-grade non-Hodgkin lymphoma (NHL) or Hodgkin lymphoma in patients with chronic lymphocytic leukemia (CLL)/small lymphocytic lymphoma (SLL). In most patients with Richter's syndrome, the high-grade NHL is diffuse large B-cell lymphoma. Only a small minority of CLL/SLL patients develop T-cell malignancies. Herein, we describe a 40-year-old male patient presenting with peripheral T-cell lymphoma not otherwise specified (PTCL-NOS) in the submandibular salivary gland, two years after the diagnosis of CLL/SLL. The PTCL-NOS consisted of small lymphocytes, which complicated diagnosis. Immunohistochemical, cytological, and molecular studies allowed the correct diagnosis of composite lymphoma (SLL/PTCL-NOS) of the submandibular salivary gland. The PTCL-NOS had a cytotoxic phenotype and aberrant expression of CD79a. There was no evidence to suggest that the PTCL-NOS of the submandibular salivary gland developed from an intimately associated submandibular lymph node or by PTCL-NOS dissemination. A review of the literature and presented case suppose that the PTCLs developed following CLL/SLL have the cytotoxic phenotype and can clinically mimic typical Richter's syndrome.
\end{abstract}

\section{Introduction}

Richter's syndrome is the development of high-grade nonHodgkin lymphoma (NHL) or Hodgkin lymphoma in patients with chronic lymphocytic leukemia (CLL)/small lymphocytic lymphoma (SLL) [1]. In most patients with Richter's syndrome, the high-grade NHL is diffuse large B-cell lymphoma. In rare cases, T-cell malignancies develop in patients with CLL/SLL. Single cases have been described of the combination of CLL/SLL and anaplastic large-cell lymphoma (ALCL) [2, 3], T-cell large granular leukemia $[4,5]$, subcutaneous panniculitis-like T-cell lymphoma [6], cutaneous gamma-delta T-cell lymphoma [7], mycosis fungoides [8], and peripheral T-cell lymphoma, not otherwise specified (PTCL-NOS) [8-12]. As some of the cases have been reported a while back [13-17], not all the peripheral T-cell lymphomas (PTCLs) have been subclassified as per the most recent World Health Organization Classification [18]. Herein, we describe an unusual manifestation of Richter's syndrome in the form of extranodal PTCL-NOS in the submandibular salivary gland.

\section{Case Presentation}

A previously healthy 38 -year-old man presented with enlarged lymph nodes in the left supraclavicular and both axillary and inguinal areas. Computed tomography also revealed an increase of mediastinal, hilar, abdominal, retroperitoneal, retrocrural, and iliac lymph nodes, as well as hepatosplenomegaly. Peripheral blood flow cytometry showed $2095 \mathrm{~B}$ cells/mL with a CLL-like immunophenotype: CD19+, CD5+, CD23+, CD38+, CD79b-/CD43+, and 


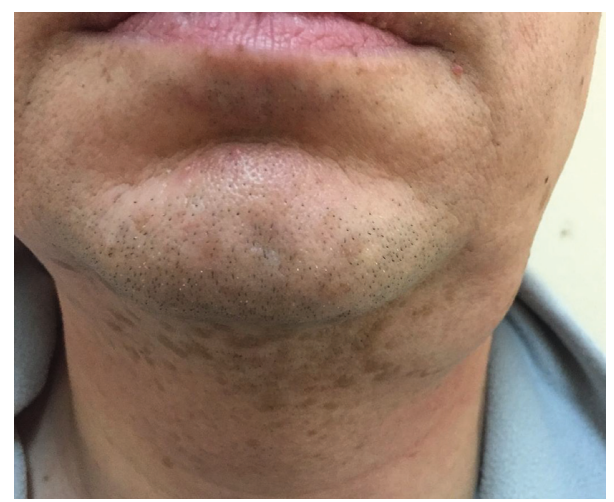

Figure 1: A mass in the left submandibular region.

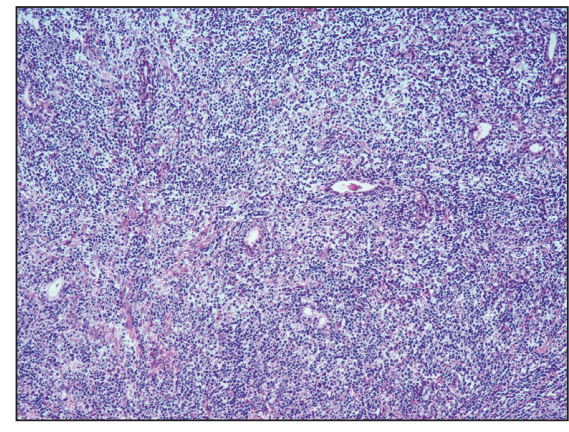

(a)

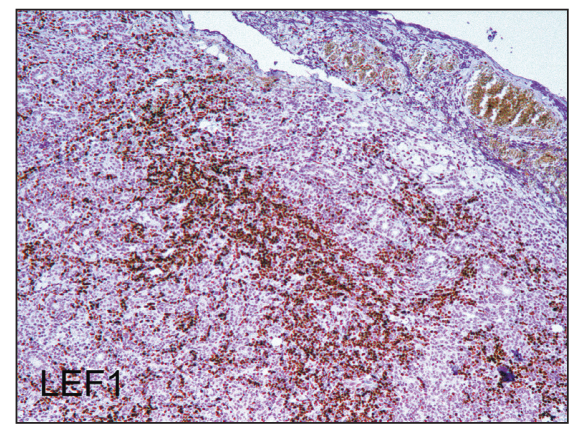

(c)

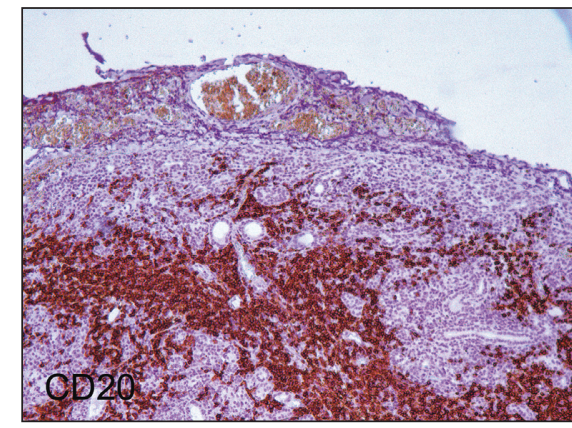

(b)

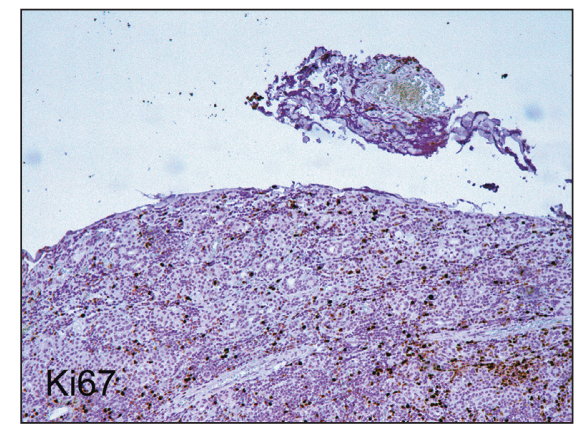

(d)

FIGURE 2: Submandibular salivary gland. (a) The architecture of the submandibular salivary gland is replaced by a diffuse small lymphocyte infiltrate H\&E staining, $\times 100$. (b) The SLL component strongly expresses CD20, highlighting focal accumulations of CD20+ B cells, $\times 100$. (c) B cells express LEF1, $\times 100$. (d) Proliferative activity marker Ki-67 in the B-cell area is expressed by up to $20 \%$ of the cells, $\times 100$.

CD22low/CD81low. Histology of an enlarged right axillary lymph node showed a distortion of the lymph node architecture by small lymphocytes expressing CD20, CD5, CD23, CD43, BCL2, and LEF1, consistent with SLL involvement. Peripheral blood mononuclear cells analyzed by FISH showed ATM (ataxia-telangiectasia mutated) gene deletion (11q23) in 25\% of nuclei. A diagnosis of CLL/SLL stage II/B (Rai/Binet) was made. During the next two years, the disease remained stable and did not require any therapy. During a monitoring visit in March 2017, the patient noted the appearance of a dense painless mass in the left submandibular area, which rapidly increased in size within a month (Figure 1). The serum lactate dehydrogenase (LDH) level was elevated to $368 \mathrm{IU} / \mathrm{L}$ (normal<225). Richter's syndrome was suspected. Ultrasound scanning and computed tomography did not allow categorical target organ identification (submandibular lymph node or submandibular salivary gland). Histologic examination revealed diffuse infiltration of the salivary gland tissue with small lymphocytes with atrophy of glandular parenchyma (Figure 2(a)). Immunohistochemical staining showed that only a part of the infiltration, mainly the focal cluster, was composed of lymphocytes expressing CD20 (Figure 2(b)), CD79a, PAX5, CD5, CD23, LEF1 (Figure 2(c)), and CD43. Up to $20 \%$ cells 


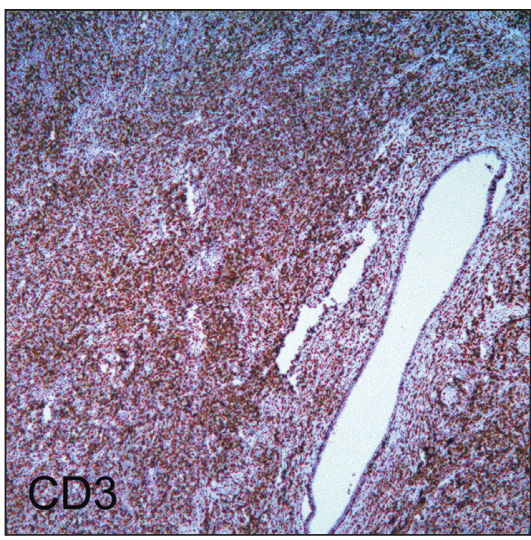

(a)

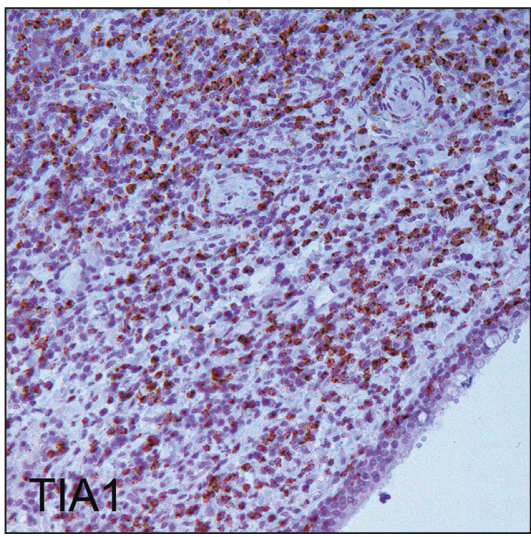

(d)

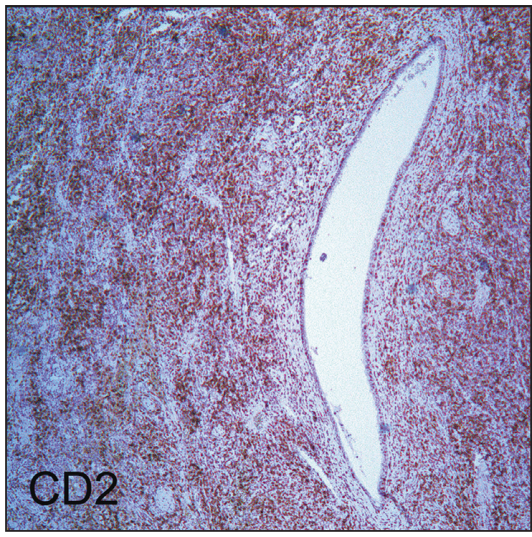

(b)

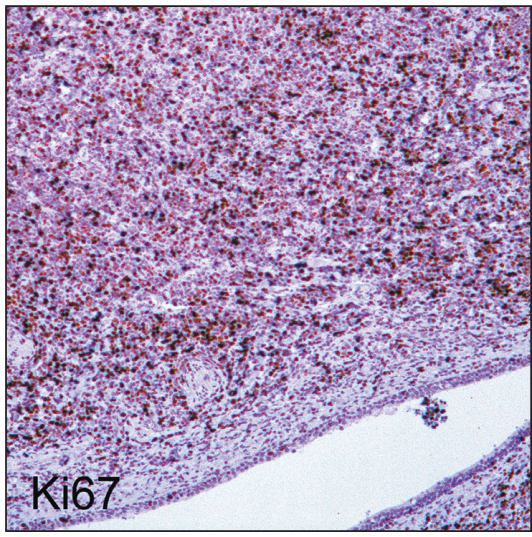

(e)

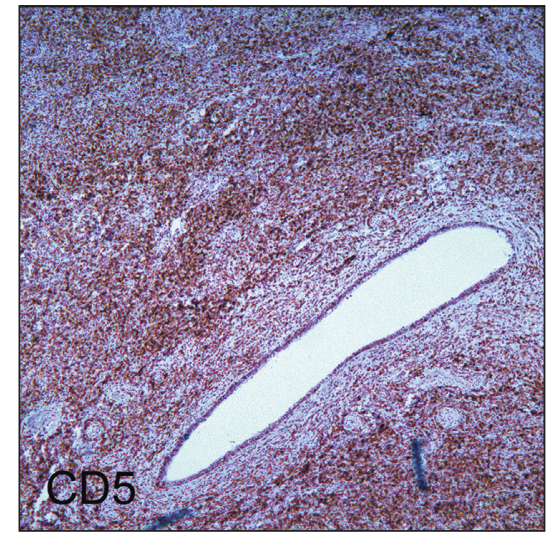

(c)

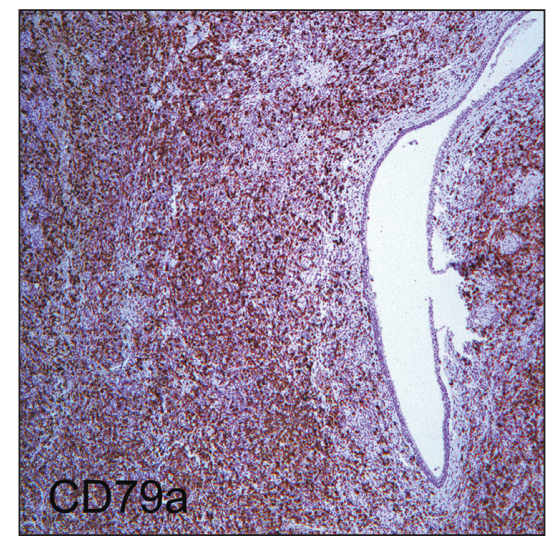

(f)

Figure 3: Submandibular salivary gland. (a) Immunohistochemistry for CD3 shows diffuse infiltration by CD3+ T cells, $\times 50$. (b) T cells express CD2, $\times 50$. (c) T cells express CD5, $\times 50$. (d) T cells express TIA1, $\times 200$. (e) Proliferative activity marker Ki-67 in the T-cell area is expressed by up to $70 \%$ of the cells, $\times 100$. (f) The neoplastic T cells coexpress CD79a, $\times 50$.

of the focal cluster expressed the proliferative activity marker Ki-67 (Figure 2(d)). The lymphoid infiltration consisted mostly of cells expressing CD2, CD3, CD5, CD7, CD8, CD43, TIA1, and granzyme B and coexpressing CD79a, with 70\% Ki-67 positivity (Figure 3). The study of imprints of the submandibular salivary gland showed two types of lymphocytes: one corresponding to CLL/SLL lymphocytes and the other with irregular nuclei and cytoplasmic granules (Figure 4). Study of the DNA extracted from freshly prepared submandibular salivary gland tissue revealed clonal IGH and clonal TCR $\beta$ gene rearrangements (Figure 5). A composite SLL/PTCL-NOS lymphoma of the submandibular salivary gland was diagnosed. Positron emission tomographycomputed tomography showed an increase in the size of the spleen, right submandibular, bilateral cervical, left supraclavicular and axillary, mediastinal, retrocrural, abdominal, retroperitoneal, and bilateral external iliac lymph nodes, with slightly increased accumulation of fluorine-18 fluorodeoxyglucose (SUV (standard uptake value) $\max =3.7$ ) as well as an enlarged pericardial lymph node in the anterior mediastinum (SUVmax $=6.1)$ (Figure 6). The patient refused a diagnostic biopsy of the pericardial lymph node, bone marrow study, and therapy. Seven months after the diagnosis of extranodal PTCL-NOS, the patient feels well.

\section{Discussion}

Composite or discordant $\mathrm{T}$ - and B-cell lymphomas are uncommon, and T-cell lymphomas associated with CLL/SLL have been only rarely reported. A review of the literature shows 11 cases of CLL/SLL with PTCL-NOS (Table 1). In 6 cases, lymphomas were discordant (CLL/SLL and PTCLNOS occurrence in separate anatomic sites), and in 5 cases, composite ones (CLL/SLL and PTCL-NOS occurrence in the same anatomical localization). In 4 cases, composite lymphoma was verified by biopsy of the lymph node, and in one case, by bone marrow biopsy. In all cases, CLL/SLL preceded PTCL-NOS, or both lymphomas were diagnosed simultaneously. In our case, SLL preceded the development of PTCL-NOS by 2 years. The rapid growth of an isolated mass in the submandibular region and increase of LDH suggested the development of Richter's syndrome. Histology revealed that the lesion was localized in the submandibular salivary gland. Diffuse infiltration of submandibular salivary gland 

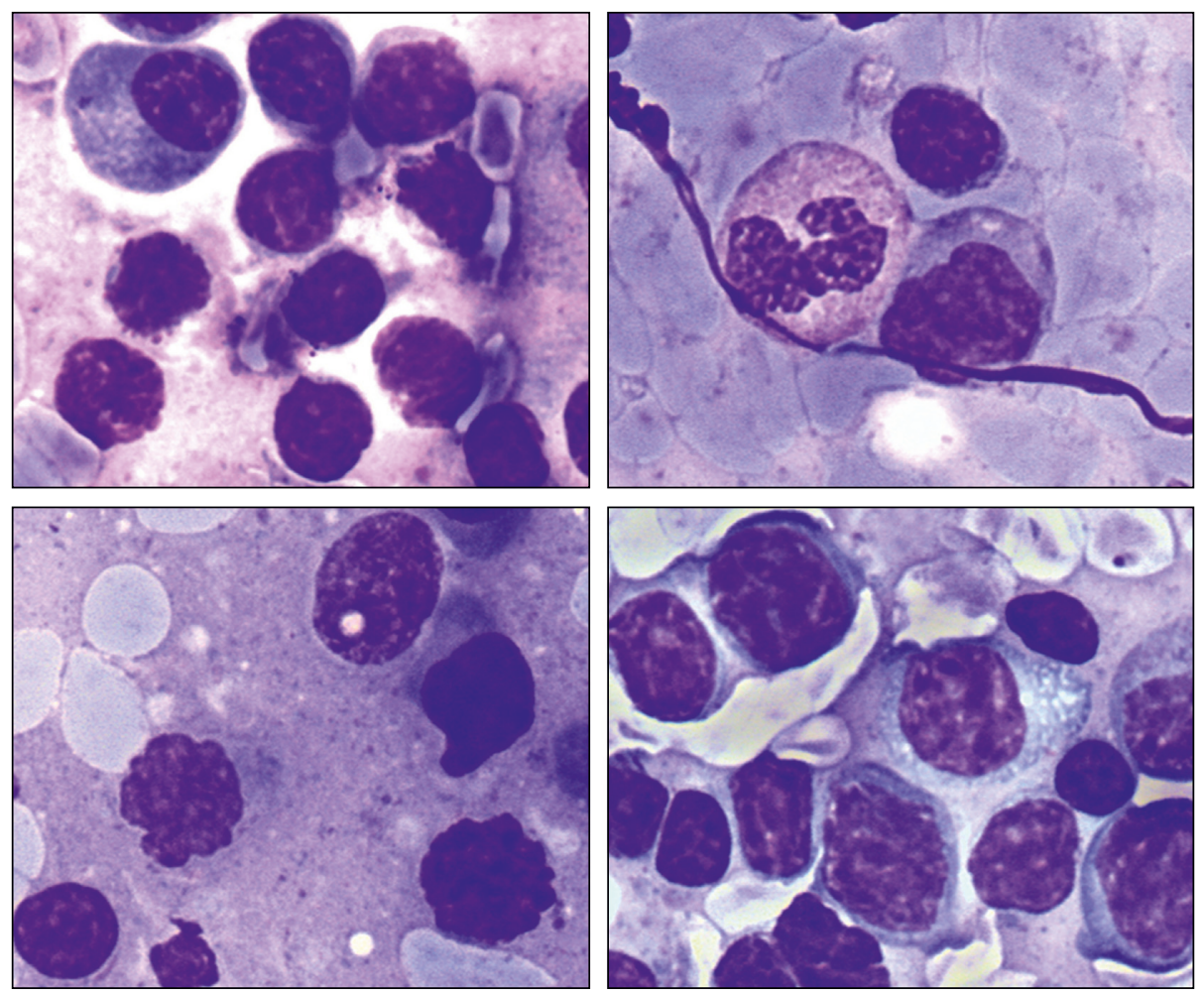

FIgURE 4: The cytology of the imprint of the submandibular salivary gland. Two lymphocyte populations can be detected. Some lymphocytes correspond to the characteristics of CLL/SLL lymphocytes. The others have an irregular shape of the nucleus, and some contain cytoplasmic granules. Romanowsky-Giemsa staining, $\times 1000$.
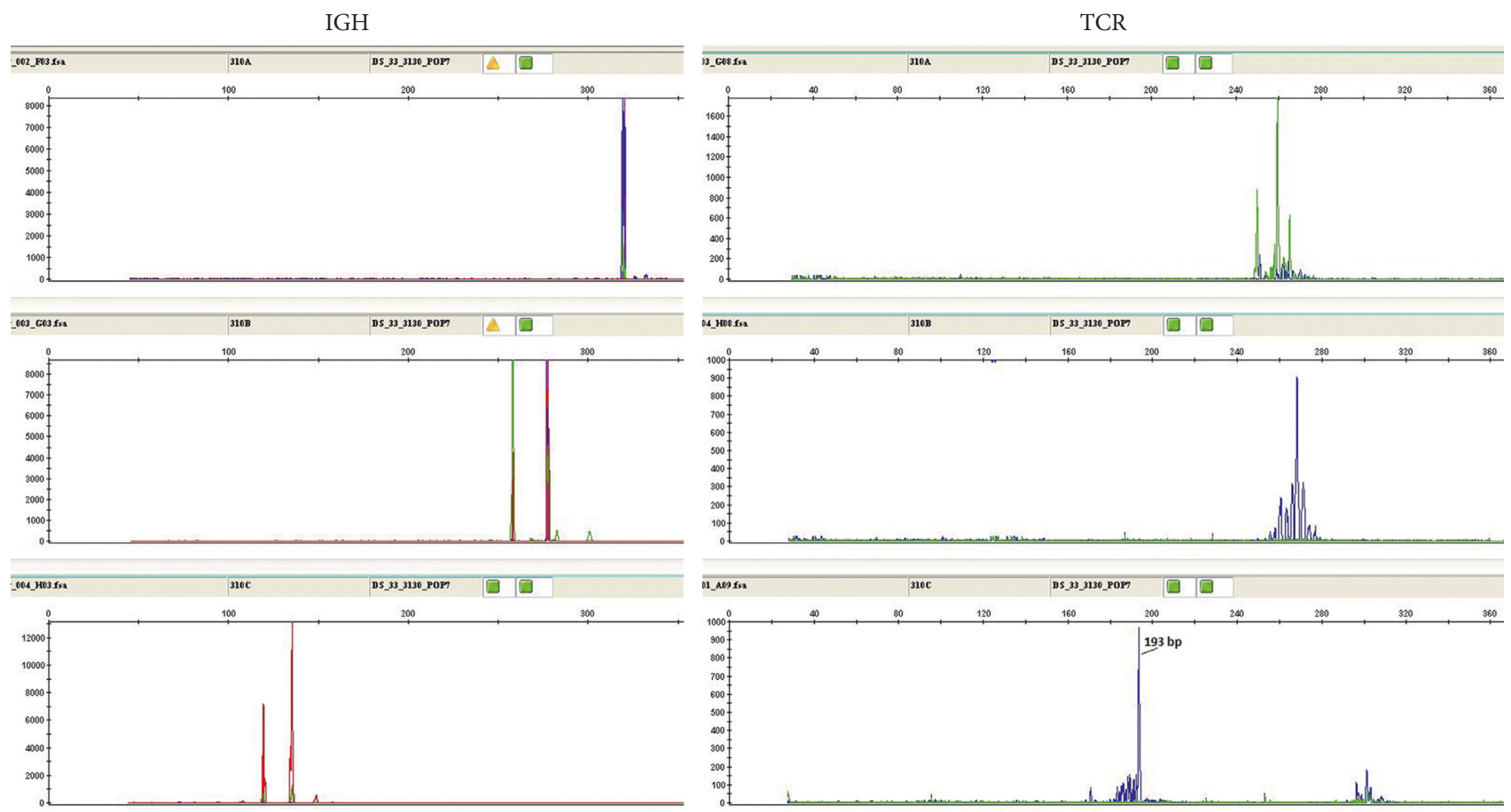

FIgURE 5: Molecular diagnostics of composite lymphoma. Clonality of the B cells and T cells was assessed for IGH and TCR $\beta$ gene rearrangements by PCR. Clonal peaks of IGH rearrangement were detected with framework I-III primers. An incomplete rearrangement was revealed of $\beta$ chain of T-cell receptor: a clonal peak at $193 \mathrm{bp}$ (panel C). 


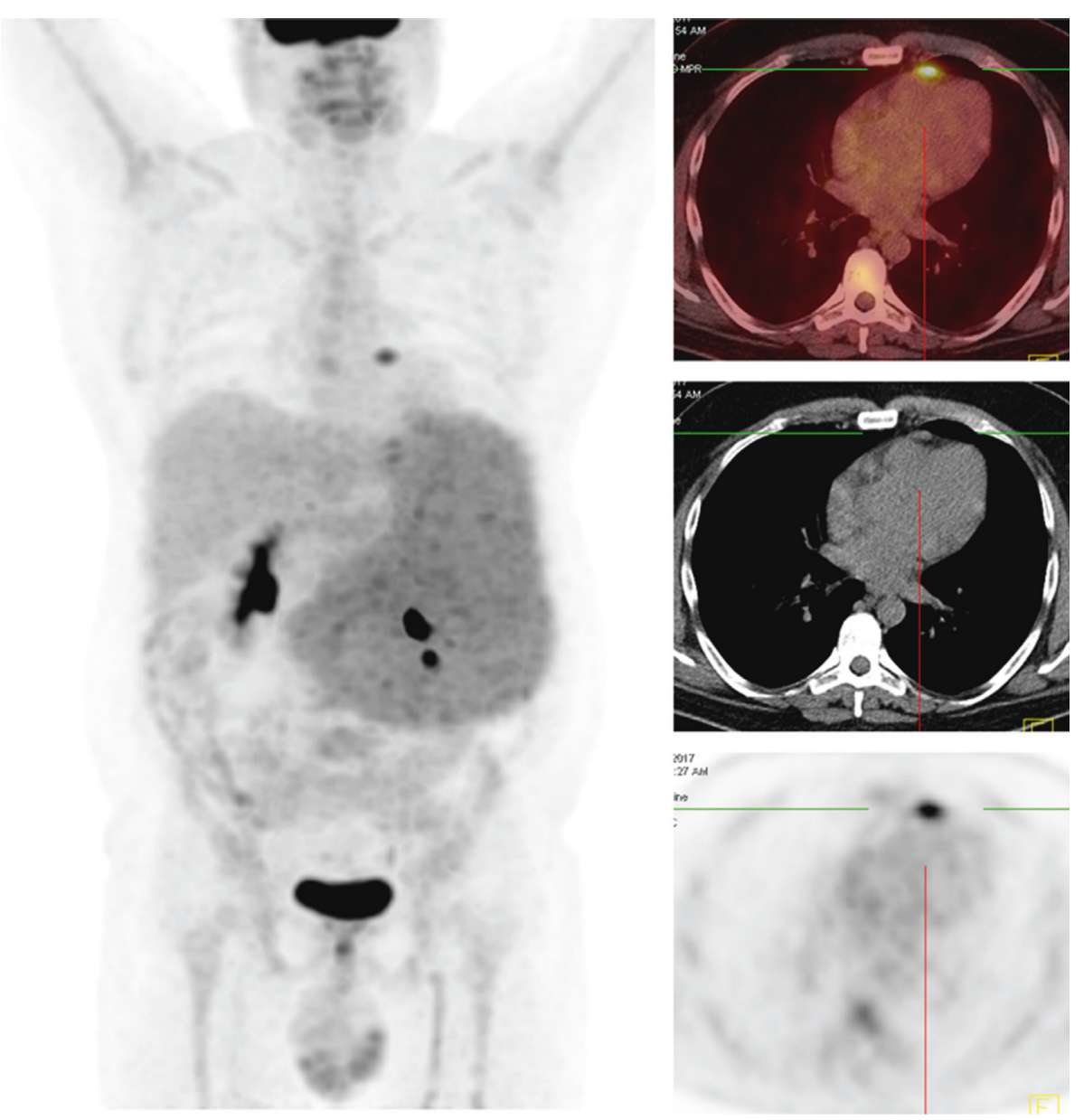

Figure 6: Positron emission tomography-computed tomography. Enlarged pericardial lymph node in the anterior mediastinum with SUVmax $=6.1$.

TABLE 1: Review of the literature for PTCL-NOS in CLL/SLL patients.

\begin{tabular}{|c|c|c|c|c|c|c|c|}
\hline \multirow[t]{2}{*}{ Authors, reference } & \multirow[t]{2}{*}{$\mathrm{Age}^{*} / \mathrm{sex}$} & \multirow{2}{*}{$\begin{array}{l}\text { Interval, } \\
\text { CLL/SLL to } \\
\text { PTCL-NOS } \\
(\mathrm{mo})\end{array}$} & \multirow{2}{*}{$\begin{array}{c}\text { Therapy for } \\
\text { CLL/SLL, } \\
\text { yes (+)/no (-) }\end{array}$} & \multicolumn{2}{|c|}{$\begin{array}{c}\text { Expression of } \\
\text { PTCL-NOS } \\
\text { cytotoxic molecules }\end{array}$} & \multirow[t]{2}{*}{$\begin{array}{l}\text { Discordant } \\
\text { lymphoma }\end{array}$} & \multirow[t]{2}{*}{$\begin{array}{l}\text { Composite } \\
\text { lymphoma } \\
\text { (localization) }\end{array}$} \\
\hline & & & & TIA1 & Granzyme B & & \\
\hline Martinez et al. [8] & $70 / \mathrm{M}$ & 156 & NA & ND & ND & + & - \\
\hline Martinez et al. [8] & $73 / \mathrm{M}$ & ND & NA & + & + & - & $+(\mathrm{LN})$ \\
\hline Martinez et al. [8] & $59 / \mathrm{M}$ & 10 & $+(\mathrm{PCT})$ & - & + & + & - \\
\hline Martinez et al. [8] & $73 / \mathrm{M}$ & 60 & $+(\mathrm{IL}-4)$ & + & + & + & - \\
\hline Martinez et al. [8] & $57 / \mathrm{M}$ & 168 & NA & + & + & + & - \\
\hline Martinez et al. [8] & $58 / \mathrm{F}$ & ND & NA & + & + & - & $+(\mathrm{LN})$ \\
\hline Campidelli et al. [9] & $80 / \mathrm{M}$ & - & - & + & + & - & $+(\mathrm{LN})$ \\
\hline Campidelli et al. [9] & $61 / \mathrm{M}$ & - & - & $\mathrm{ND}$ & + & - & $+(\mathrm{BM})$ \\
\hline Buddula and Assad [10] & $66 / \mathrm{M}$ & 72 & $+(\mathrm{PCT})$ & + & + & + & - \\
\hline Alomari et al. [11] & $68 / \mathrm{F}$ & 84 & $+(\mathrm{PCT} / \mathrm{RT})$ & - & + & - & $+(\mathrm{LN})$ \\
\hline Boyer et al. [12] & $70 / \mathrm{M}$ & 132 & $+($ PCT $)$ & ND & + & + & - \\
\hline
\end{tabular}

* At PTCL-NOS diagnosis; LN: lymph node; BM: bone marrow; PCT: polychemotherapy; RT: radiotherapy; IL-4: interleukin 4; NA: not available; ND: not done; PTCL-NOS: peripheral T-cell lymphoma not otherwise specified; CLL/SLL: chronic lymphocytic leukemia/small lymphocytic lymphoma; TIA1: T-cell intracellular antigen-1. 
TAвLE 2: Review of the literature for peripheral T-cell lymphomas with aberrant CD79a expression.

\begin{tabular}{|c|c|c|c|c|c|}
\hline \multirow{2}{*}{ Authors, reference } & \multirow{2}{*}{ Age/sex } & \multicolumn{2}{|c|}{ Lymphoma localization } & \multicolumn{2}{|c|}{ Expression of cytotoxic molecules } \\
\hline & & Lymph node & Extranodal & TIA1 & Granzyme B \\
\hline Blakolmer et al. [19] & $77 / \mathrm{M}$ & - & Nose & + & + \\
\hline Blakolmer et al. [19] & $63 / \mathrm{M}$ & - & Jejunum & + & + \\
\hline Blakolmer et al. [19] & $42 / \mathrm{M}$ & - & Jejunum & + & + \\
\hline Blakolmer et al. [19] & $45 / \mathrm{M}$ & - & Stomach & + & + \\
\hline Yao et al. [20] & $76 / \mathrm{M}$ & - & Left adrenal gland & + & ND \\
\hline Bo et al. [21] & $77 / \mathrm{M}$ & + & - & + & + \\
\hline Matnani et al. [22] & $75 / \mathrm{M}$ & + & - & ND & ND \\
\hline
\end{tabular}

ND: not done; TIA1: T-cell intracellular antigen-1.

tissue by small lymphocytes initially suggested SLL origin. Unlike other reports that have described a composite SLL and PTCL-NOS lymphoma $[8,9,11]$, in our case, PTCL consisted of small lymphocytes, which precluded histological verification. The discrepancy in the clinical picture (rapid growth of the tumor) and the unspecific histological picture prompted us to conduct further studies. Immunohistochemistry showed a cytotoxic (CD8+, TIA1+, and granzyme $\mathrm{B}+$ ) $\mathrm{T}$-cell infiltrate with high proliferative activity (70\% Ki-67 positivity), with infiltrating B-lymphocytes foci of CLL/SLL immunophenotype showing significantly less proliferative activity (20\% Ki-67 positivity). Molecular analysis detected monoclonal rearrangement of the IGH and TCR $\beta$ genes in the infiltrating cells. Cytological study of imprints of the submandibular salivary gland revealed two different lymphoid populations. Thus, a combination of immunohistochemistry, molecular, and cytological studies allowed the diagnosis of composite SLL/PTCL-NOS lymphoma of the submandibular salivary gland.

The two lymphomas in the submandibular salivary gland were not clearly delineated, which made it difficult to assess their immunophenotype. Nevertheless, a careful evaluation of the immunohistochemical picture of the composite lymphoma uncovered the aberrant expression of CD79a by T cells of PTCL-NOS. Literature shows 7 cases of peripheral T-cell lymphomas with aberrant CD79a expression [19-22] (Table 2), and in all 6 cases where the expression of cytotoxic molecules was evaluated, tumor T cells had a cytotoxic phenotype. In addition, 5 out of 7 cases were extranodal lymphomas.

Salivary gland lymphomas account for approximately $5 \%$ of all extranodal lymphomas [23], $1 \%$ to $2 \%$ of all salivary gland neoplasms [24], and about $10 \%$ of all salivary gland malignancies [25]. Lymphomas of the salivary glands are biologically heterogeneous and inevitably include genuine extranodal lymphomas and nodal-type lymphomas, with the latter arising in intrasalivary lymph nodes [26]. It can be difficult to distinguish between the two types because the lymphoma cells often spill over into the adjacent tissues. The definition of a true primary salivary gland lymphoma is an issue. Schmid et al. reported that if a lesion has no capsulelike structure reminiscent of an expanded lymph node capsule and no lymph nodes, it can be defined as a true primary salivary gland lymphoma [27]. The majority of salivary gland lymphomas are of B-cell lineage. In contrast, primary salivary gland T-cell and NK-cell lymphomas are extremely rare. To the best of our knowledge, only 16 such cases have been reported [28-34]. Nine cases were parotid salivary gland lymphomas (one case with intrasalivary gland lymph nodal origin), 5 were submandibular salivary gland lymphomas, and 2 were sublingual salivary gland lymphomas. Histological subtypes were variable and included PTCL-NOS, ALCL, NK-cell lymphoma, and adult T-cell lymphoma/leukemia. In our case, there was no evidence to suggest that the PTCL-NOS of the submandibular salivary gland developed from an intimately associated submandibular lymph node or PTCL-NOS dissemination.

The pathogenesis of PTCL-NOS lymphoma arising in association with CLL/SLL is not well understood, and several hypotheses may be conceived. It is intriguing that all cases of PTCL-NOS reported in CLL/SLL patients expressed cytotoxic granule proteins (Table 1, except one case where data were unavailable), in contrast to T-cell lymphomas in the general population $[35,36]$. In our case, the PTCL-NOS also expressed cytotoxic proteins: TIA1 and granzyme B. Cytotoxic T-cell lymphomas are often associated with chronic antigenic stimulation or chronic immunosuppression [37]. The decreased immunosurveillance accompanying CLL/SLL is well documented, and studies of cellular immunity in CLL/SLL patients have found reduced T-cell function with a paradoxical clonal expansion of CD8+ T cells [8] and increased circulating CD8+ T-cell counts [38]. Theoretically, this could increase the incidence of T-cell large granular leukemia in CLL/SLL patients, but only 2 cases of such an association are described in the literature $[4,5]$.

The second possibility is the exposure to chemotherapy for CLL/SLL that induces a secondary neoplasm. Information on CLL/SLL therapy before the development of PTCL-NOS was provided for only 7 of 11 patients (Table 1). Four patients received multiagent chemotherapy including fludarabine, one patient received experimental therapy with interleukin 4 , and in 2 patients, therapy was not administered (since both lymphomas were diagnosed simultaneously). In our patient, before development of PTCL-NOS, the CLL/SLL therapy was not indicated [39], and we adhered to the wait-and-watch approach.

It is unusual that the patient is feeling well without therapy within seven months after diagnosis of extranodal PTCL. We believe that the total resection of submandibular salivary gland resulted in the complete removal of the 
primary extranodal T-cell lymphoma. The assumption is supported by the PET-CT. However, we cannot definitively interpret the enlarged pericardial lymph node in the anterior mediastinum with the SUVmax $=6.1$. Such an SUV can be observed in the lymph node lesion by both SLL [40] and PTCL as well [41].

We believe this is the first reported case of composite lymphoma (SLL/PTCL-NOS) of the submandibular salivary gland. A feature of this case was the absence of histological signs, indicating the presence of a second lymphoma in the salivary gland initially affected by SLL. The PTCL-NOS consisted of small lymphocytes with a cytotoxic phenotype and aberrant CD79a expression.

\section{Data Access}

The datasets used and/or analyzed during the current study are available from the corresponding author on reasonable request.

\section{Ethical Approval}

This study was reviewed and approved by the V.A. Nasonova Research Institute of Rheumatology, Russian Academy of Medical Sciences Institutional Review Board.

\section{Consent}

Written informed consent was obtained from the patient for publication of this case report and any accompanying images.

\section{Conflicts of Interest}

The authors declare that they have no conflicts of interest.

\section{References}

[1] A. M. Tsimberidou and M. J. Keating, "Richter syndrome: biology, incidence, and therapeutic strategies," Cancer, vol. 103, no. 2, pp. 216-228, 2005.

[2] T. Liu, M. He, D. L. Carlson, C. Hedvat, and J. TeruyaFeldstein, "ALK-positive anaplastic large cell lymphoma in a patient with chronic lymphocytic leukemia," International Journal of Surgical Pathology, vol. 18, no. 5, pp. 424-428, 2008.

[3] G. A. Nai, B. Cabello-Inchausti, and S. Suster, "Anaplastic large cell lymphoma of the spleen," Pathology-Research and Practice, vol. 194, no. 7, pp. 517-522, 1998.

[4] J. F. Lesesve, P. Feugier, T. Lamy et al., "Association of B-chronic lymphocytic leukaemia and T-large granular lymphocyte leukaemia," Clinical and Laboratory Haematology, vol. 22, no. 2, pp. 121-122, 2000.

[5] A. M. Plata, J. N. Frame, J. Stuelpnagel, T. Juranovic, O. C. Estalilla, and T. M. Jelic, "Development of T-cell large granular lymphocytic leukemia in the course of B-cell chronic lymphocytic leukemia with a causal relationship inferred from a flow cytometric analysis of the bone marrow aspirate," Pathology Discovery, vol. 3, no. 1, p. 4, 2015.

[6] J. C. Sluzevich, M. R. Hall, and V. Roy, "Subcutaneous panniculitis-like T-cell lymphoma after rituximab," Journal of the American Academy of Dermatology, vol. 67, no. 5, pp. e223-e225, 2012.
[7] J. Guitart, D. D. Weisenburger, A. Subtil et al., "Cutaneous gamma-delta T-cell lymphomas: a spectrum of presentations with overlap with other cytotoxic lymphomas," American Journal of Surgical Pathology, vol. 36, no. 11, pp. 1656-1665, 2012.

[8] A. Martinez, S. Pittaluga, N. Villamor et al., "Clonal T-cell populations and increased risk for cytotoxic T-cell lymphomas in B-CLL patients: clinicopathologic observations and molecular analysis," American Journal of Surgical Pathology, vol. 28, no. 7, pp. 849-858, 2004.

[9] C. Campidelli, E. Sabattini, M. Piccioli et al., "Simultaneous occurrence of peripheral T-cell lymphoma unspecified and B-cell small lymphocytic lymphoma. Report of 2 cases," Human Pathology, vol. 38, no. 5, pp. 787-792, 2007.

[10] A. Buddula and D. Assad, "Peripheral T-Cell lymphoma manifested as gingival enlargement in a patient with chronic lymphocytic leukemia," Journal of Indian Society of Periodontology, vol. 15, no. 1, pp. 67-69, 2011.

[11] A. Alomari, P. Hui, and M. Xu, "Composite peripheral T-cell lymphoma not otherwise specified, and B-cell small lymphocytic lymphoma presenting with hemophagocytic lymphohistiocytosis," International Journal of Surgical Pathology, vol. 21, no. 3, pp. 303-308, 2013.

[12] D. F. Boyer, N. I. Lindeman, N. L. Harris, and J. A. Ferry, "Peripheral T-cell lymphomas with cytotoxic phenotype in patients with chronic lymphocytic leukemia/small lymphocytic lymphoma," American Journal of Surgical Pathology, vol. 38, no. 2, pp. 279-288, 2014.

[13] J. G. Strickler, T. W. Amsden, and P. J. Kurtin, "Small B-cell lymphoid neoplasms with coexisting T-cell lymphomas," American Journal of Clinical Pathology, vol. 98, no. 4, pp. 424-429, 1992.

[14] A. Lee, M. E. Skelly, D. W. Kingma, and L. Jeffrey Medeiros, "B-cell chronic lymphocytic leukemia followed by high grade T-cell lymphoma. An unusual variant of Richter's syndrome," American Journal of Clinical Pathology, vol. 103, no. 3, pp. 348-352, 1995.

[15] L. V. Abruzzo, L. M. Griffith, M. Nandedkar et al., "Histologically discordant lymphomas with B-cell and T-cell components," American Journal of Clinical Pathology, vol. 108 , no. 3, pp. 316-323, 1997.

[16] A. Novogrudsky, E. L. Amorosi, and S. R. Gottesman, "High-grade T-cell lymphoma complicating B-cell chronic lymphocytic leukemia: an unusual manifestation of "Richter's syndrome"," American Journal of Hematology, vol. 66, no. 3, pp. 203-206, 2001.

[17] J. I. Martin-Subero, R. Siebert, L. Harder et al., "Cytogenetic and molecular characterization of a patient with simultaneous B-cell chronic lymphocytic leukemia and peripheral T-cell lymphoma," American Journal of Hematology, vol. 68, no. 4, pp. 276-279, 2001.

[18] S. Swerdlow, E. Campo, N. Harris et al., WHO Classification Tumours of Haematopoietic and Lymphoid Tissues, IARC, Lyon, France, 4th edition, 2008.

[19] K. Blakolmer, M. Vesely, J. A. Kummer, W. Jurecka, C. Mannhalter, and A. Chott, "Immunoreactivity of B-cell markers (CD79a, L26) in rare cases of extranodal cytotoxic peripheral T-(NK/T-) cell lymphomas," Modern Pathology, vol. 13, no. 7, pp. 766-772, 2000.

[20] X. Yao, J. Teruya-Feldstein, M. Raffeld, L. Sorbara, and E. S. Jaffe, "Peripheral T-cell lymphoma with aberrant expression of CD79a and CD20: a diagnostic pitfall," Modern Pathology, vol. 14, no. 2, pp. 105-110, 2001.

[21] W. Bo, K. Mei, W. Zhaoming, Y. Hongtian, B. Yanfeng, and N. Xiaoying, "CD79a positive T cell lymphoma with 
bone marrow involvement," Pathology, vol. 43, no. 7, pp. 737-740, 2011.

[22] R. G. Matnani, R. L. Stewart, J. Pulliam, C. D. Jennings, and M. Kesler, "Peripheral T-cell lymphoma with aberrant expression of CD19, CD20, and CD79a: case report and literature review," Case Reports in Hematology, vol. 2013, Article ID 183134, pp. 1-5, 2013.

[23] C. Freeman, J. W. Berg, and S. J. Cutler, "Occurrence and prognosis of extranodal lymphomas," Cancer, vol. 29, no. 1, pp. 252-260, 1972.

[24] M. J. Gleeson, M. H. Bennett, and R. A. Cawson, "Lymphomas of salivary glands," Cancer, vol. 58, no. 3, pp. 699-704, 1986.

[25] J. J. Sciubba, P. L. Auclari, and G. L. Ellis, Malignant Lymphomas in Surgical Pathology of the Salivary Glands, G. L. Ellis, P. L. Auclair, and D. R. Gnepp, Eds., Saunders, Philadelphia, PA, USA, 1991.

[26] P. G. Isaacson and A. J. Norton, Extranodal Lymphomas, Churchill Livingstone, Edinburgh, England, 1994.

[27] U. Schmid, D. Helbron, and K. Lennert, "Primary malignant lymphomas localized in salivary glands," Histopathology, vol. 6, no. 6, pp. 673-687, 1982.

[28] H. Takahashi, N. Tsuda, F. Tezuka, S. Fujita, and H. Okabe, "Non-Hodgkin's lymphoma of the major salivary gland: a morphologic and immunohistochemical study of 15 cases," Journal of Oral Pathology and Medicine, vol. 19, no. 7, pp. 306-312, 1990.

[29] M. James, A. J. Norton, and A. B. Akosa, "Primary T-cell lymphoma of submandibular salivary gland," Histopathology, vol. 22, no. 1, pp. 83-85, 1993.

[30] J. K. Chan, W. Y. Tsang, P. K. Hui et al., "T- and T/natural killer-cell lymphomas of the salivary gland: a clinicopathologic, immunohistochemical and molecular study of six cases," Human Pathology, vol. 28, no. 2, pp. 238-245, 1997.

[31] S. Wen, Y. Mizugaki, F. Shinozaki, and K. Takada, "EpsteinBarr virus (EBV) infection in salivary gland tumors: lytic EBV infection in nonmalignant epithelial cells surrounded by EBV-positive T-lymphoma cells," Virology, vol. 227, no. 2, pp. 484-487, 1997.

[32] W. S. R. Hew, F. A. Carey, N. M. Kernohan, A. D. Heppleston, R. Jackson, and R. F. Jarrett, "Primary T cell lymphoma of salivary gland: a report of a case and review of the literature," Journal of Clinical Pathology, vol. 55, no. 1, pp. 61-63, 2002.

[33] T. Miyagi, A. Nagasaki, T. Taira et al., "Extranodal adult T-cell leukemia/lymphoma of the head and neck: a clinicopathological study of nine cases and a review of the literature," Leukemia \& Lymphoma, vol. 50, no. 2, pp. 187-195, 2009.

[34] N. Yanagawa, M. Osakabe, H. Furuse, K. Maeda, and G. Tamura, "Peripheral T-cell lymphoma arising from an intraglandular lymph node in the parotid gland: a case report and literature review," Pathology International, vol. 62, no. 1, pp. 60-64, 2012.

[35] P. Went, C. Agostinelli, A. Gallamini et al., "Marker expression in peripheral T-cell lymphoma: a proposed clinicalpathologic prognostic score," Journal of Clinical Oncology, vol. 24, no. 16, pp. 2472-2479, 2006.

[36] E. S. Jaffe, L. Krenacs, and M. Raffeld, "Classification of cytotoxic T-cell and natural killer cell lymphomas," Seminars in Hematology, vol. 40, no. 3, pp. 175-184, 2003.

[37] P. Kanavaros, M. L. Boulland, B. Petit, and B. Arnulf, "Expression of cytotoxic proteins in peripheral T-cell and natural killer-cell (NK) lymphomas: association with extranodal site, NK or T gamma-delta phenotype, anaplastic morphology and CD30 expression," Leukemia \& Lymphoma, vol. 38, no. 3-4, pp. 317-326, 2000.
[38] C. L. Goolsby, M. Kuchnio, W. G. Finn, and L. Peterson, "Expansions of clonal and oligoclonal $\mathrm{T}$ cells in B-cell chronic lymphocytic leukemia are primarily restricted to the CD3(+)CD8(+) T-cell population," Cytometry, vol. 42, no. 3, pp. $188-195,2000$.

[39] D. Oscier, C. Dearden, E. Erem et al., "Guidelines on the diagnosis, investigation and management of chronic lymphocytic leukaemia," British Journal of Haematology, vol. 159, pp. 541-564, 2012.

[40] T. Papajık, M. Myslivecek, R. Urbanova et al., "2-[18F]fluoro2-deoxy-D-glucose positron emission tomography/computed tomography examination in patients with chronic lymphocytic leukemia may reveal Richter transformation," Leukemia \& Lymphoma, vol. 55, no. 2, pp. 314-319, 2014.

[41] J. Feeney, S. Horwitz, M. Gönen, and H. Schöder, "Characterization of T-cell lymphomas by FDG PET/CT," American Journal of Roentgenology, vol. 195, no. 2, pp. 333-340, 2010. 


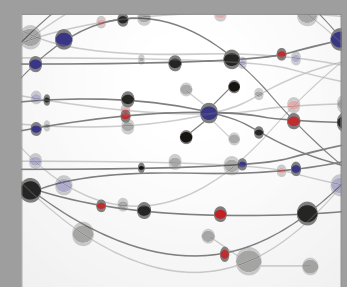

The Scientific World Journal
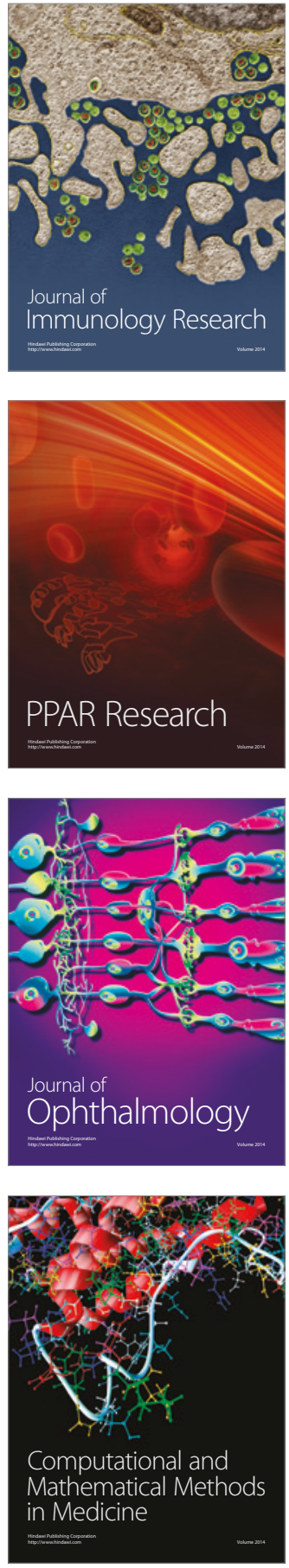

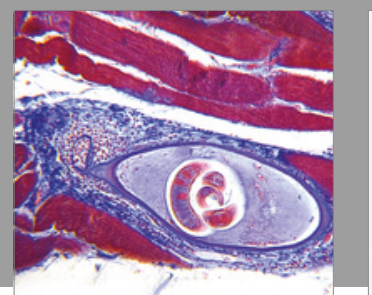

Gastroenterology Research and Practice
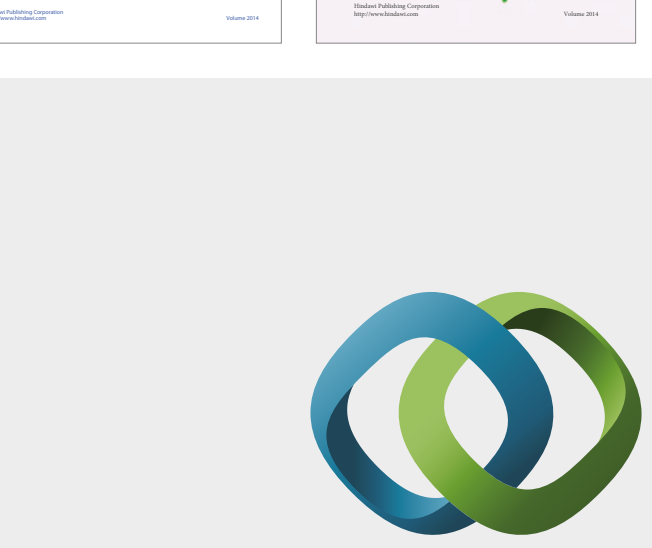

\section{Hindawi}

Submit your manuscripts at

https://www.hindawi.com
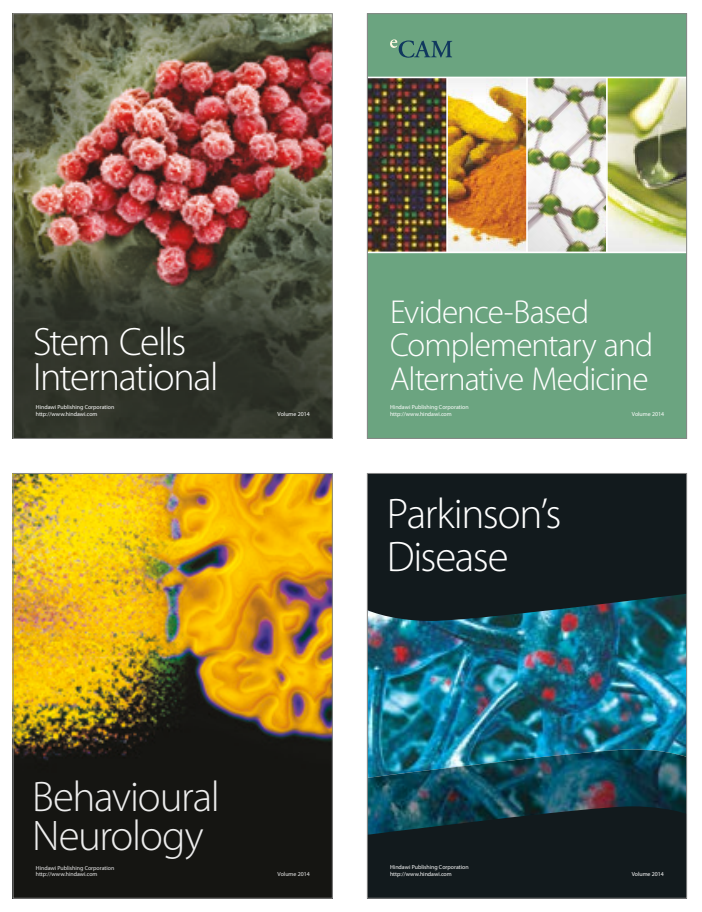
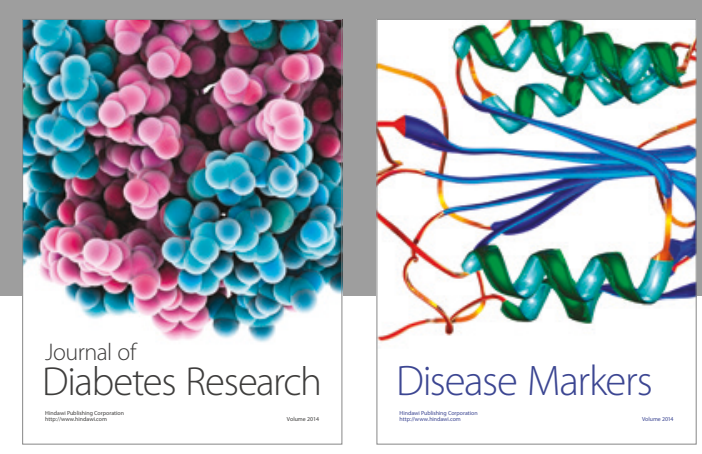

Disease Markers
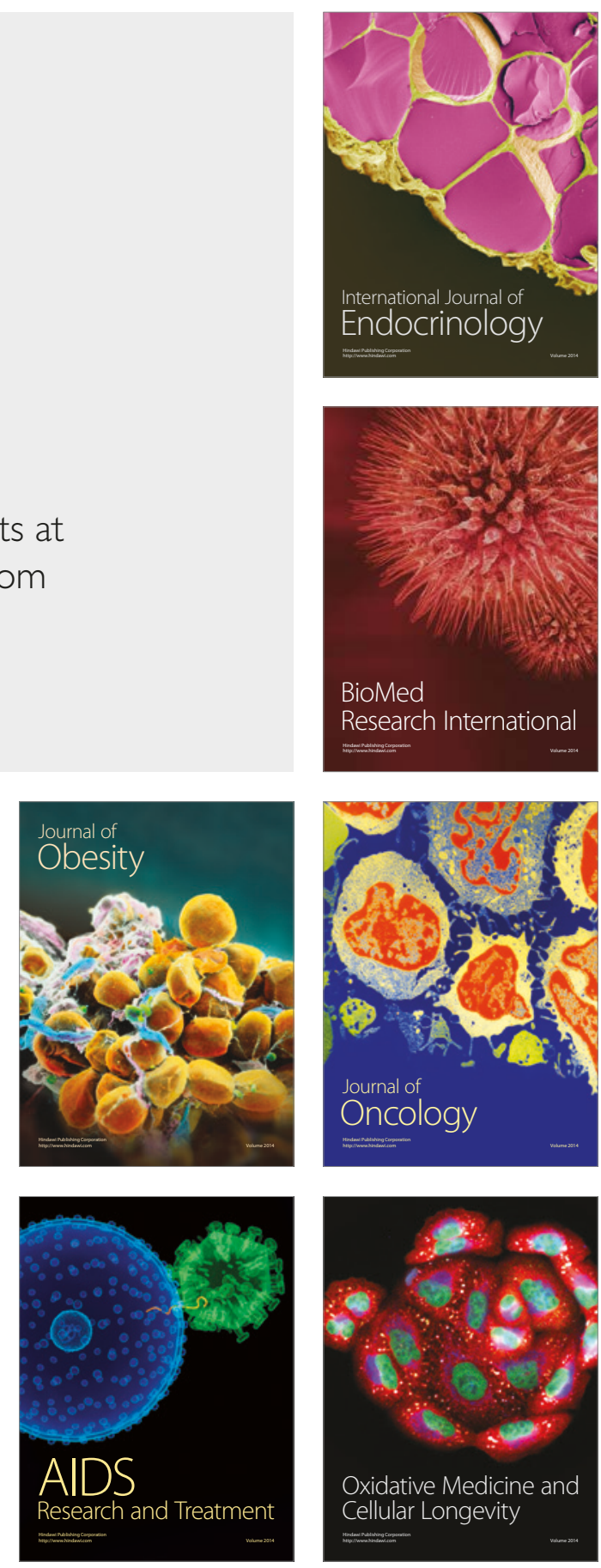